\title{
ICON 2019—International Scientific Tendinopathy Symposium Consensus: There are nine core health- related domains for tendinopathy (CORE DOMAINS): Delphi study of healthcare professionals and patients
}

\author{
Bill Vicenzino (1) , ${ }^{1}$ Robert-Jan de Vos, ${ }^{2}$ Hakan Alfredson 다, ${ }^{3}$ Roald Bahr, \\ Jill L Cook, ${ }_{1}^{6}$ Brooke K Coombes, ${ }^{7}$ Siu Ngor Fu ${ }^{8}$ Karin Gravare Silbernagel (1) , ${ }^{9}$ \\ Alison Grimaldi, ${ }^{1,10}$ Jeremy S Lewis (1) ${ }^{11,12,13}$ Nicola Maffulli, ${ }^{14,15,16}$ \\ SP Magnusson, ${ }^{17,18}$ Peter Malliaras, ${ }^{19}$ Sean Mc Auliffe, ${ }^{5}$ Edwin H G Oei, ${ }^{20}$ \\ Craig Purdam, ${ }^{6}$ Jonathan D Rees 이, ${ }^{21,22}$ Ebonie Kendra Rio, ${ }^{6}$ Alex Scott $\left({ }^{2},{ }^{23}\right.$ \\ Cathy Speed ${ }_{1}^{24}$ Inge van den Akker-Scheek, ${ }^{25}$ Adam Weir, ${ }^{2,26,27}$ \\ Jennifer Moriatis Wolf, ${ }^{28}$ Johannes Zwerver (1) ${ }^{29}$
}

\begin{abstract}
- Additional material is published online only. To view please visit the journal online (http://dx.doi.org/10.1136/ bjsports-2019-100894).
\end{abstract}

For numbered affiliations see end of article.

\section{Correspondence to}

Professor Bill Vicenzino, School of Health and Rehabilitation Sciences: Physiotherapy, The University of Queensland, Brisbane, Queensland, Australia; b.vicenzino@uq.edu.au

Accepted 15 September 2019 Published Online First 4 November 2019
Check for updates

(C) Author(s) (or their employer(s)) 2020. No commercial re-use. See rights and permissions. Published by BMJ.

To cite: Vicenzino $B$ de Vos R-J, Alfredson $\mathrm{H}$ et al. Br J Sports Med 2020:54:444-451.

\begin{abstract}
Background The absence of any agreed-upon tendon health-related domains hampers advances in clinical tendinopathy research. This void means that researchers report a very wide range of outcome measures inconsistently. As a result, substantial synthesis/metaanalysis of tendon research findings is almost futile despite researchers publishing busily. We aimed to determine options for, and then define, core healthrelated domains for tendinopathy.
\end{abstract}

Methods We conducted a Delphi study of healthcare professionals (HCP) and patients in a three-stage process. In stage 1, we extracted candidate domains from clinical trial reports and developed an online survey. Survey items took the form: 'The 'candidate domain' is important enough to be included as a core healthrelated domain of tendinopathy'; response options were: agree, disagree, or unsure. In stage 2, we administered the online survey and reported the findings. Stage 3 consisted of discussions of the findings of the survey at the ICON (International Scientific Tendinopathy Symposium Consensus) meeting. We set $70 \%$ participant agreement as the level required for a domain to be considered 'core'; similarly, 70\% agreement was required for a domain to be relegated to 'not core' (see Results next).

Results Twenty-eight HCP (92\% of whom had $>10$ years of tendinopathy experience, $71 \%$ consulted $>10$ cases per month) and 32 patients completed the online survey. Fifteen HCP and two patients attended the consensus meeting. Of an original set of 24 candidate domains, the ICON group deemed nine domains to be core. These were: (1) patient rating of condition, (2) participation in life activities (day to day, work, sport), (3) pain on activity/loading, (4) function, (5) psychological factors, (6) physical function capacity, (7) disability, (8) quality of life and (9) pain over a specified time. Two of these $(2,6)$ were an amalgamation of five candidate domains. We agreed that seven other candidate domains were not core domains: range of motion, pain on clinician applied test, clinical examination, palpation, drop out, sensory modality pain and pain without other specification. We were undecided on the other five candidate domains of physical activity, structure, medication use, adverse effects and economic impact. Conclusion Nine core domains for tendon research should guide reporting of outcomes in clinical trials. Further research should determine the best outcome measures for each specific tendinopathy (ie, core outcome sets).

\section{INTRODUCTION}

If we review the past two decades of tendinopathy research, it appears that progress in patient outcomes is on a plateau. ${ }^{12}$ One factor that may have limited progress is that few tendon studies have lent themselves to meta-analysis, ${ }^{34}$ so that the clinical and research community has not agreed on treatment guidelines for the major tendinopathies. A specific barrier to meta-analysis of tendon treatment studies is that the original research studies report many disparate outcome measures, ${ }^{3-5}$ most of which have not been validated. ${ }^{6}$ A prerequisite for authors to be able to synthesise and meta-analyse research findings from different studies systematically is for numerous studies to contain similar outcome measures. It can help to guide a field of clinical research if core outcomes are proactively defined and established as a core outcome set. ${ }^{7}$

Before a community of researchers adopt core outcomes widely, the key actors usually first agreeupon core domains. Let us explain the important difference and their logical sequence. The ultimate goal, a core outcome set, refers to validated outcome measures that capture core health-related domains specific to a condition that have been agreed-upon by patients and healthcare professionals (HCP: clinicians and researchers). A very successful example comes from the Outcome Measures in Rheumatology (OMERACT) initiative ${ }^{8}$ where researchers and patients developed a conceptual framework to identify core domains (first) before defining a core outcome set. ${ }^{9}$ This approach guided our study and this consensus statement is limited to the first part-determining core domains. The next phase 
for tendon researchers, developing core outcome measures for specific tendinopathies, is planned for 2020 and beyond.

We aimed to establish (health-related) core domains for tendinopathy. We used a three-stage process: (1) a literature review of clinical trials on tendinopathy, which informed the items (candidate domains) to be included in an online survey, (2) an online survey of HCP and patients seeking their opinion on key domains, and finally (3) a consensus meeting of HCP and patients to make decisions on what should be the core domains.

\section{METHODS}

We conducted a consensus process involving HCP and patients, which commenced with some of us generating candidate domains from a review of literature (stage 1, June 2018). These candidate domains were then considered for their importance as core health-related domains in tendinopathy, first by online survey (stage 2, August 2018) and then at an in-person meeting at the 2018 International Scientific Tendinopathy Symposium (ISTS, Groningen, the Netherlands) (stage 3, September 2018). The consensus process described here was one of three separate projects discussed at the ISTS consensus meeting; the other two dealt with terminology ${ }^{10}$ and reporting of participant characteristics. ${ }^{11}$

\section{Participants}

To achieve a representative group of tendinopathy experts, we selected the HCP cohort based on their track record primarily, with consideration for a balance of different professional disciplines, sex, likely attendance at the ISTS consensus meeting and geographical distribution. The aim was to have an online cohort of approximately 30 participating HCP, with as many of these to attend the dedicated consensus meeting the day before the ISTS symposium. This number of participants is based on previous Delphi studies in similar areas and regarded as an optimal sample size to answer our research question. ${ }^{12}$ All participants signed an agreement (online supplementary appendix A) when they accepted the invitation to participate. This stipulated the expectations of participation, as well as the rules for the consensus process and authorship of publications.

We aimed to recruit at least 30 patients. For this, we used two research databases of patients with verified upper and lower limb tendinopathies on clinical or clinical plus imaging examination in Brisbane and Melbourne (Australia). The patients on these databases were invited to complete the online survey. The head of the local scientific committee of ISTS at Groningen (JZ) asked two patients from their clinical research unit to participate during the consensus meeting. These patients were proficient in English so they could participate in the survey and engage in the Englishlanguage meeting.

Informed consent was obtained from all participants.

\section{Procedure stage 1-identifying outcome measures and formulating} a candidate domain list

The candidate domain list was formed by first undertaking a scoping review of published clinical trials in tendinopathy between 2008 and 2018. This generated 122 relevant papers and one investigator (BV) extracted all outcome measures reported in those trials. For rigour, a research assistant independently extracted outcomes from a random selection of $20 \%$ of those papers, which were then crosschecked. The aim was to generate the broadest possible capture of outcomes from which the survey's candidate domain list was derived.

To move from outcome measures to domains, investigators JZ, SMcA, EKR, AS, BV and AW then constructed a list of potential domains that would make up the items of the survey. The aim was not to consolidate domains at this stage, but to ensure that all outcomes were aligned to a potential domain. To guide us, we used the International Classification of Functioning (ICF) aligned (https://www.who.int/classifications/icf/en/) OMERACT core areas of (1) life impact, (2) pathophysiological manifestations, (3) resource use and (4) death. ${ }^{9}$

Procedure stage 2-online survey relating to candidate domains The candidate domains formed the basis of the online survey (online supplementary appendix B). Each candidate domain was included as a separate survey question taking the form 'Is the domain "candidate domain" important enough to be included in a Core Domain Set for Tendinopathy?' and included examples of the outcome measures that were aligned with the candidate domain (online supplementary appendix B and Results for alignment).

Survey respondents had three options in response to each question: agree (yes), disagree (no) or unsure. The consensus committee (JZ, EKR, AS, AW, SMcA, BV) made an a-priori criterion decision that $\geq 70 \%$ of 'agree' responses would elevate a candidate domain into the 'core' and $\geq 70 \%$ of disagree responses would relegate the candidate domain to not being considered as a core domain. ${ }^{913}$ The candidate domains that fell between these limits of agreement ('unsure') were the focus of our discussion session at the ISTS consensus meeting.

\section{Procedure stage 3-ISTS 2018 consensus meeting}

The results from the online survey were collated (online supplementary appendix C) and circulated to all HCP and the two patients 10 days prior to the consensus meeting. At the consensus meeting, the candidate domains that had been voted as 'unsure' (ie, not already included or excluded from the domain set) were discussed in turn. HCP and patients (ie, the group members) then voted as to whether they 'agreed' or 'disagreed' with each candidate being a core domain (forced choice). As with the online survey, a domain had to earn $\geq 70 \%$ of the delegates' votes for either 'agree' or 'disagree' to be classified into either of those categories.

\section{RESULTS}

\section{Participants-HCP}

Thirty HCP were invited to participate in the overall Delphi process (potentially all three stages) and 28 responded to the online survey (one did not respond within the timeframe and one withdrew after agreeing to participate due to personal reasons, unrelated to the survey). Most of the cohort were clinician-researchers with at least 11 years working in the field and most (68\%) had suffered from tendinopathy personally at some point.

Of these 28 individuals, 15 (54\%) attended the ISTS consensus meeting in Groningen on the 26 September 2018 (table 1). The meeting group was representative of the online survey group in terms of sex, cases of tendinopathy consulted per month, years of clinical experience in the field of tendinopathy and having a tendinopathy. There were proportionally more physiotherapists than medical professionals at the meeting. No surgeons attended the consensus meeting (table 1).

\section{Participants-patient partners}

All 219 patients registered on the research centres' databases were sent an email inviting them to participate in the survey, with 56 (26\%) clicking on the survey link, of which $32(57 \%)$ then provided consent and completed the survey. A 55-year-old woman with Achilles tendinopathy not related to a specific sports participation and a 30-year-old man who was a former elite 
Consensus statement

Table 1 Characteristics of the participants completing the online survey and attending the consensus meeting

\begin{tabular}{|c|c|c|c|c|}
\hline \multirow[b]{2}{*}{ Characteristic } & \multicolumn{2}{|l|}{ Survey } & \multicolumn{2}{|l|}{ Meeting } \\
\hline & Healthcare professionals & Patients & Healthcare professionals & Patients \\
\hline $\mathrm{N}$ & 28 & 31 & 15 & 2 \\
\hline Sex: female & $10(36)$ & $24(77)$ & $6(40)$ & $1(50)$ \\
\hline Age: median (IQR; min-max) years & $53(43-59 ; 29-64)$ & $53(32-61 ; 18-71)$ & $46(40-55 ; 29-64)$ & $43(36-49 ; 30-55)$ \\
\hline \multicolumn{5}{|l|}{ Role } \\
\hline Clinician only & 0 & $1(3)$ & 0 & 0 \\
\hline Researcher/scientist only & $5(18)$ & 0 & $3(20)$ & 0 \\
\hline Clinician and researcher & $23(82)$ & 0 & $12(80)$ & 0 \\
\hline Neither clinician nor researcher/scientist & 0 & $28(97)$ & 0 & $2(100)$ \\
\hline Tendinopathy cases per month & & NA & & NA \\
\hline None & $5(18)$ & & $3(20)$ & \\
\hline At least 4 & $1(4)$ & & $1(6.7)$ & \\
\hline Between 5 and 10 & $2(7)$ & & $2(13.3)$ & \\
\hline Between 11 and 15 & $7(25)$ & & $6(40)$ & \\
\hline More than 16 & $13(46)$ & & $3(20)$ & \\
\hline Years managing tendon problems & 127 & NA & & NA \\
\hline None & 0 & & $1(6.7)$ & \\
\hline At least 4 & 0 & & 0 & \\
\hline Between 5 and 10 & $2(4)$ & & $3(20)$ & \\
\hline Between 11 and 15 & $6(22)$ & & $3(20)$ & \\
\hline More than 16 & $19(70)$ & & $8(53.3)$ & \\
\hline Highest academic qualification & 126 & & & \\
\hline Undergraduate diploma/certificate & 0 & $5(16)$ & 0 & 0 \\
\hline Bachelor & 0 & $14(45)$ & 0 & $1(50)$ \\
\hline Master & $1(4)$ & $4(13)$ & 0 & $1(50)$ \\
\hline $\mathrm{PhD}$ & $23(88)$ & $5(16)$ & $13(86.7)$ & 0 \\
\hline Clinical doctorate & $2(8)$ & 0 & $1(6.7)$ & 0 \\
\hline Other & 0 & $3(10)$ & $1(6.7)$ & 0 \\
\hline \multicolumn{5}{|l|}{ Healthcare profession (some cited more than one) } \\
\hline Physiotherapy & $13(40.6)$ & & $9(56)$ & \\
\hline Sports and exercise medicine physician & $8(28.6)$ & & $3(18.8)$ & \\
\hline Orthopaedic surgery & $4(12.5)$ & & $0(0)$ & \\
\hline Rheumatology & $3(9.4)$ & & $1(6.3)$ & \\
\hline Radiology & $1(3.1)$ & & $1(6.3)$ & \\
\hline Human movement science & $1(3.1)$ & & $1(6.3)$ & \\
\hline Epidemiology & $1(3.1)$ & & $1(6.3)$ & \\
\hline Surgery & $1(3.1)$ & & $0(0)$ & \\
\hline Currently have tendon problem & $8(29)$ & $26(84)$ & $4(26.7)$ & $2(100)$ \\
\hline History of tendon problem & $19(68)$ & $21(68)$ & $10(66.7)$ & $1(50)$ \\
\hline \multicolumn{5}{|l|}{ Country where work } \\
\hline Australia & $8(28.6)$ & $31(100)$ & $5(33.3)$ & \\
\hline UK & $5(17.9)$ & & $1(6.7)$ & \\
\hline The Netherlands & $5(17.9)$ & & $4(26.7)$ & $2(100)$ \\
\hline Canada & $2(7.1)$ & & $1(6.7)$ & \\
\hline USA & $2(7.1)$ & & $1(6.7)$ & \\
\hline Denmark & $2(7.1)$ & & $1(6.7)$ & \\
\hline Qatar & $1(3.6)$ & & $1(6.7)$ & \\
\hline Sweden & $1(3.6)$ & & 0 & \\
\hline Hong Kong & $1(3.6)$ & & $1(6.7)$ & \\
\hline Norway & $1(3.6)$ & & 0 & \\
\hline
\end{tabular}

Unless otherwise stated, data are N (\%). 2 (6.5) physiotherapists, 1 (3.2) nurse midwife, 1 (3.2) social worker, 1 (3.2) athlete.

NA, not applicable.

middle-distance runner with Achilles tendinopathy, both from Groningen, participated during the ISTS consensus meeting.

\section{Domains}

Stage 1 resulted in 24 candidate domains (table 2), which formed the basis of the questions in the Delphi process. In addition to these 24 candidate domains, we asked survey participants to nominate any potential (candidate) tendon health-related domains they would remove, add or combine/amalgamate. We collated responses from the survey and sent them in a report out to attendees 10 days before the ISTS consensus meeting in Groningen (online supplementary appendix C).

From the HCP online survey, three candidate domains reached the predetermined $\geq 70 \%$ agree (or disagree) criterion. Pain on 
Table 2 Domains considered in the meeting in response to the question 'Is the 'candidate domain (item)' important enough to be included in a core domain set for tendinopathy?'

\begin{tabular}{|c|c|c|c|c|}
\hline Domain & Description/definition (example outcome) & $\begin{array}{l}\text { Consensus } \\
\text { meeting \% }\end{array}$ & $\begin{array}{l}\text { Survey }(\mathrm{HCP} \text {; } \\
\text { P) } \%\end{array}$ & $\begin{array}{l}\text { Some typical consensus meeting discussion } \\
\text { points }\end{array}$ \\
\hline \multicolumn{5}{|c|}{ Core domains (candidate domains (items) agreed $\geq 70 \%$ agree) } \\
\hline $\begin{array}{l}\text { Participant/patient rating overall } \\
\text { condition }\end{array}$ & $\begin{array}{l}\text { A single assessment numerical evaluation (eg, rate your } \\
\text { tendon status where } 100 \% \text { is no problems and } 0 \% \\
\text { worst case scenario, global rating of change (how are } \\
\text { you now compared with prior treatment), }{ }^{18-20} \text { patient } \\
\text { acceptable symptom status (Is your current symptom } \\
\text { level acceptable?)). }\end{array}$ & 100 & 61,91 & $\begin{array}{l}\text { Considered to be the most patient-centred candidate } \\
\text { domain. }\end{array}$ \\
\hline \multirow[t]{4}{*}{ Participation } & $\begin{array}{l}\text { A patient rating of the level of participation/ } \\
\text { engagement across areas of their life. (eg, ratings of } \\
\text { level of sport and time to return to sport). }{ }^{21}\end{array}$ & 94 & * & $\begin{array}{l}\text { This resulted from the discussion on the three } \\
\text { candidate domains considered in the survey and } \\
\text { at the meeting, which were overall, sport and } \\
\text { work participation. With the exception of the sport } \\
\text { participation domain where the patients agreed it } \\
\text { ought to be a core domain, this candidate domain } \\
\text { did not reach agreement in the survey. Comments } \\
\text { in the survey suggested amalgamation, which was } \\
\text { supported at the meeting. }\end{array}$ \\
\hline & $\begin{array}{l}\text { Overall (eg, time to return to work, level of work } \\
\text { (strenuousness)). }\end{array}$ & * & 25,65 & \\
\hline & Sport participation & * & 57,74 & \\
\hline & Work participation & * & 46,65 & \\
\hline Pain on loading/activity & $\begin{array}{l}\text { Participant/patient reported intensity of pain on } \\
\text { performing a task/activity that loads the tendon. } \\
\text { (eg, VAS or NRS for pain intensity when the patient } \\
\text { performs a tendon-specific pain-provocative task). }{ }^{22-24}\end{array}$ & $\dagger$ & 93,97 & $\begin{array}{l}\text { This was strongly agreed at the survey by both } \\
\text { patients and HCP. Note that there were no } \\
\text { disagreements. Tendon-specific loading tests would } \\
\text { need to be determined (eg, pain on gripping an } \\
\text { object by a patient with lateral elbow tendinopathy). }\end{array}$ \\
\hline Function & $\begin{array}{l}\text { Participant/patient rated level of function (and not } \\
\text { referring to the intensity of their pain; eg, Patient } \\
\text { Specific Function Scale on a VAS or NRS). }{ }^{19}\end{array}$ & 88 & 68,87 & $\begin{array}{l}\text { Discussion centred around possible interdependence } \\
\text { with Disability, which was resolved by considering } \\
\text { this candidate domain as 'how much can the patient } \\
\text { do' as opposed to the level of disability due to the } \\
\text { pain. }\end{array}$ \\
\hline Psychological factors & $\begin{array}{l}\text { Psychology (eg, pain self efficacy, pain } \\
\text { catastrophisation, kinesiophobia, anxiety or depression } \\
\text { scales). }\end{array}$ & 88 & 36,77 & $\begin{array}{l}\text { There was some concern regarding interdependence } \\
\text { with Quality of Life (QoL), both at the meeting and } \\
\text { HCP survey. It was agreed that psychology was } \\
\text { sufficiently important and broader than covered in } \\
\text { QoL. }\end{array}$ \\
\hline \multirow[t]{2}{*}{ Physical function capacity } & $\begin{array}{l}\text { Quantitative measures of physical tasks performed in } \\
\text { clinic (eg, number of hops, timed stair walk, number of } \\
\text { single limb squats, including dynamometry (strength) } \\
\text { and wearable technology). }{ }^{192526}\end{array}$ & 88 & 57,68 & $\begin{array}{l}\text { Some discussion about the differences between this } \\
\text { and 'function', but resolved as this is a quantitative } \\
\text { measure of the physical capacity (eg, number of } \\
\text { repetitions of or time to do a task, muscle force/ } \\
\text { torque) and not a patient rating of their function (eg, } \\
\text { measured with a patient-specific function scale). }\end{array}$ \\
\hline & $\begin{array}{l}\text { Muscle capacity or 'strength' as it was considered in } \\
\text { the survey and meeting. }\end{array}$ & * & 36,91 & $\begin{array}{l}\text { Muscle capacity of strength was merged under } \\
\text { physical function capacity as it was considered a } \\
\text { physical function measure and there was a high } \\
\text { patient agreement at survey. It was rejected as a } \\
\text { separate domain at the meeting ( } 12.5 \% \text { agree) }\end{array}$ \\
\hline Disability & $\begin{array}{l}\text { Composite scores of a mix of patient-rated pain and } \\
\text { disability due to the pain, usually relating to tendon- } \\
\text { specific activities/tasks (eg, VISA scales, }{ }^{19} 202324 \\
\text { patient-rated tennis elbow evaluation, }{ }^{27} \text { disability of } \\
\text { the arm, shoulder and hand). }\end{array}$ & $t$ & 86,69 & $\begin{array}{l}\text { This was agreed at the survey stage and not } \\
\text { discussed at the meeting. }\end{array}$ \\
\hline QoL & $\begin{array}{l}\text { The general well being of the individual (specific QoL } \\
\text { questionnaires such as European QoL - } 5 \text { Dimension } \\
\text { (EQ-5D), Australian QoL (AQoL), 36-item Short Form } \\
\text { survey (SF-36). } 192027\end{array}$ & 75 & 57,91 & $\begin{array}{l}\text { There was concern that there is no tendon-specific } \\
\text { QoL measure, but that the overall well being of the } \\
\text { individual was important to include as a domain. }\end{array}$ \\
\hline \multirow[t]{2}{*}{ Pain over a specified time } & $\begin{array}{l}\text { Participant reported pain intensity over a period of time } \\
\text { (morning, night, } 24 \text { hours, a week; eg, VAS, NRS). }{ }^{27-29}\end{array}$ & 75 & 32,69 & $\begin{array}{l}\text { The initial candidate domain was pain over } 24 \text { hours, } \\
\text { but also referred to a period of time. After discussion, } \\
\text { it was agreed that it was the 'timeframe' being } \\
\text { specified that provided more utility (eg, for some } \\
\text { tendons morning pain, others night). }\end{array}$ \\
\hline & & & & Continued \\
\hline
\end{tabular}


Consensus statement

Table 2 Continued

\begin{tabular}{|c|c|c|c|c|}
\hline Domain & Description/definition (example outcome) & $\begin{array}{l}\text { Consensus } \\
\text { meeting \% }\end{array}$ & $\begin{array}{l}\text { Survey }(\mathrm{HCP} \text {; } \\
\text { P) } \%\end{array}$ & $\begin{array}{l}\text { Some typical consensus meeting discussion } \\
\text { points }\end{array}$ \\
\hline
\end{tabular}

Candidate domains (items) not reaching $\geq 70 \%$ agree

Candidate domains (items) no

Physical activity

Physical activity Overall physical activity levels (eg, self-report of physical activity levels, wearable sensor technology).
69

54,81

(2)

Discussion centred around possible interdependence and overlap with other domains. Along with this being less specific to tendinopathy compared with what some of the other domains might be, it did not reach agreement. The $69 \%$ agreement could be viewed as indicating the overlap concern, but that this domain was one requiring further consideration.

\begin{tabular}{llrr}
\hline Structure & Tendon tissue characteristics (eg, MRI, US, biopsy). & 69 & 43,34 \\
& & \\
& & \\
Medication use & $\begin{array}{l}\text { Medicines used (eg, patient report or record of type } \\
\text { and dose). }\end{array}$ & 63 & 57,74
\end{tabular}

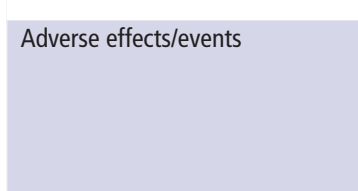

Economic impact: costs

\begin{abstract}
Unwanted unintended effects of treatments (eg, patient $56 \quad 50,58$ report or medical record).
\end{abstract}

Not core domains ( $\geq 70 \%$ disagree)

\begin{tabular}{|c|c|c|c|c|}
\hline $\begin{array}{l}\text { Pain elicited with clinician applied } \\
\text { stress/examination }\end{array}$ & $\begin{array}{l}\text { Rating of pain when a clinician does an examination of } \\
\text { the patient (eg, VAS or NRS for pain intensity). }\end{array}$ & 21 & 18,61 & $\begin{array}{l}\text { Considered more to be for diagnosis and selection } \\
\text { into studies. }\end{array}$ \\
\hline Clinical examination findings & $\begin{array}{l}\text { Clinician report of examination findings (eg, usually a } \\
\text { composite score of a number of clinical examination } \\
\text { tests). }\end{array}$ & 13 & 29,75 & $\begin{array}{l}\text { Considered important in a clinical examination, but } \\
\text { the composite nature was not meaningful as an } \\
\text { outcome. }\end{array}$ \\
\hline Palpation & $\begin{array}{l}\text { Manual pressure elicited/evoked pain over the tendon } \\
\text { (eg, VAS, NRS). }\end{array}$ & 13 & 39,68 & $\begin{array}{l}\text { Considered not to be related to resolution and } \\
\text { difficult for some tendons (eg, Shoulder vs Achilles). }\end{array}$ \\
\hline Range of motion & Range of motion (eg, goniometer, inclinometer). & $\dagger$ & 11,84 & $\begin{array}{l}75 \% \text { disagree HCP survey and not voted at the } \\
\text { meeting. }\end{array}$ \\
\hline Drop out or discontinue treatment & Ceasing a treatment (eg, patient or clinical record). & 6 & 46,61 & $\begin{array}{l}\text { While considered important to be reported in clinical } \\
\text { trials, it was not a key domain. Reiteration that } \\
\text { candidate domains like this should still be reported } \\
\text { as per other guidelines of reporting. }\end{array}$ \\
\hline Sensory modality specific pain & $\begin{array}{l}\text { Pain thresholds/tolerance to sensory stimulation (eg, } \\
\text { quantitative sensory testing). }\end{array}$ & 6 & 11,42 & $\begin{array}{l}\text { Considered likely useful in subgrouping studies but } \\
\text { not as an outcome for trials. }\end{array}$ \\
\hline Pain without further specification & $\begin{array}{l}\text { Patient asked about their pain without reference to } \\
\text { activity or timeframe (eg, VAS, NRS). }\end{array}$ & 0 & 25,63 & $\begin{array}{l}\text { Covered better in pain on loading and over a } \\
\text { specified timeframe. }\end{array}$ \\
\hline
\end{tabular}

Note that the citations placed in the definition column are only examples of some authors reporting of indicative outcome measures and they are not to be read as endorsing either the outcomes or their use.

${ }^{*}$ Amalgamated items (candidate domains).

†Met the agreed criterion prior to meeting and thus not discussed at the meeting.

CONSORT, Consolidated Standards of Reporting Trials; HCP, Health Care Professionals; MRI, Magnetic Resonance Imaging; NRS, Numeric Rating Scale; QoL, Quality of Life; US,

Ultrasound; VAS, Visual Analogue Scale; VISA, Victorian Institute of Sports Assessment.

activity/loading and disability were voted as core domains and range of motion voted as not appropriate to be a core domain.

From the patient online survey, 11 candidate domains were voted as core domains (see online supplementary appendix C). No candidate domains met the $\geq 70 \%$ disagree criterion. Pain on activity/loading was the only candidate domain that was voted into the core domain by both patients and HCP.

At the ISTS consensus meeting, attendees moved seven candidate domains from an 'unsure' status to $\geq 70 \%$ agreement which elevated them to core domain status (table 2): these seven were: patient rating of condition, participation, function, psychological factors, physical function capacity, quality of life and pain over a specified time. As explained in table 2, function is patient rated (eg, as might be captured on a patient-specific function scale) whereas physical function capacity is a quantitative measure of function (eg, strength measured on dynamometer).

Attendees at the ISTS consensus meeting amalgamated five separate candidate domains from the survey into two core 
Table 3 Brief overview of the findings (at the $70 \%$ core/not-core threshold)*

\begin{tabular}{ll}
\hline $\begin{array}{l}\text { Voted as 'a core domain when reporting } \\
\text { patient outcomes in tendinopathy' ( } \geq 70 \% \\
\text { agreement) }\end{array}$ & $\begin{array}{l}\text { Voted as 'not a core domain } \\
\text { when reporting patient } \\
\text { outcomes in tendinopathy' } \\
(\geq 70 \% \text { agreement) }\end{array}$ \\
\hline $\begin{array}{l}\text { Patient rating of condition } \\
\text { Pain on activity/loading }\end{array}$ & $\begin{array}{l}\text { Range of motion } \\
\text { Pain on clinician examination }\end{array}$ \\
\hline Function & Clinical examination findings \\
\hline $\begin{array}{l}\text { Psychological factors } \\
\text { Disability }\end{array}$ & Palpation \\
\hline $\begin{array}{l}\text { Physical function capacity (including strength) } \\
\text { Quality of life }\end{array}$ & Pain without further specification \\
\hline $\begin{array}{l}\text { Pain over a specified timeframe } \\
\text { *See table } 2 \text { for details (and for those candidate domains remaining undecided). } \\
\text { †Candidate domains amalgamated to one domain. }\end{array}$
\end{tabular}

domains. The core domain of participation was introduced as an amalgamation of candidate domains of participation in sport, work and global participation. The core domain of physical function capacity was the amalgamation of physical function and strength.

Seven candidate domains reached the $\geq 70 \%$ voting threshold for agreement that they should not serve as core domains (table 2). Four of these involved clinician examination (ie, pain on clinician examination, examination findings, palpation, range of motion). Pain without further specification (ie, context) was deemed to be more precisely covered under the two domains, pain on loading/activity and pain over specified time. Drop outs and sensory modality specific pain were the others.

We were undecided on the other five candidate domains: physical activity, structure, medication use, adverse effects and economic impact.

An infographic that conveys the salient design features and results has been developed to assist in the implementation of the ICON 9 core domains (online supplementary file 4).

\section{DISCUSSION}

Brief overview of the findings (at the $70 \%$ core/not-core threshold) is presented in table 3 .

\section{What might the nine core domains mean?}

The nine core domains reflect how HCPs and patients understand the nature of tendinopathy. They encompass both physical (eg, pain on loading, aspects of participation, function, physical function capacity, disability), psychosocial (eg, psychological factors, aspects of participation and pain ratings) and overall status/life impact (eg, patient rating of condition and quality of life).

There was a $100 \%$ agreement that pain could not be measured without reference to context (eg, either to an activity or over a defined period). That is, ratings of pain intensity should be made on the basis of some specific activity, loading or time point/ timeframe.

Six of the seven core domains decided at the ISTS consensus meeting (two having reached the 70\% agree threshold prior at the survey stage) had reached the core domain inclusion criterion in the online survey of patients. The six core domains of patient rating of condition, participation, function, physical function capacity, psychological factors and quality of life were agreed-upon by both HCP and patients. This adds weight to our belief that these domains are meaningful health-related domains for tendinopathy. When HCP and patients agree on domains, OMERACT refers to them as 'inner' core domains. ${ }^{9}$ We recommend that outcome measures used in research and clinical practice align with each of these core domains, but does not prevent the inclusion of other outcome measures.

\section{What comes next? We will need to define core outcome measures}

The next stage will be for HCP with relevant expertise and patients with tendinopathies to establish the core outcome measures (ie, core outcome sets) that align with each of the core domains for the different regional tendinopathies. ${ }^{9}$ Many of the domains specifically relate to tasks, activities, sports/recreational pursuits and work/occupations that load a specific tendon. For example, specific activities, tasks and sport/occupations that are associated with Achilles tendinopathy (eg, distance running) are likely very different to those associated with patellar tendinopathy (eg, jumping sports) or lateral elbow tendinopathy (eg, racquet sports, golf, manual labour). Now that we have determined nine core domains for tendinopathy the ICON group resolved to establish anatomic site-specific working groups to establish core outcome sets for each of the common tendinopathies. An example of a protocol for developing core outcomes for Achilles tendinopathy can be seen in the Core Outcome Measures in Effectiveness Trials (COMET) database (http:// www.comet-initiative.org/studies/details/1323).

\section{Structure morphology of tendon (as captured by tendon imaging modalities)}

The concept of tendon structure did not reach the $70 \%$ threshold to be considered a core domain. In the survey, 34\% of HCPs and $43 \%$ of patients voted that structure should be a domain. After much discussion at the ISTS consensus meeting, 69\% of participants voted that structure should be a core domain.

The main reason for resistance to structure being a core domain related to imaging. Imaging appearance of tendon has a variable and at present unclear relationship with symptoms and it has low diagnostic utility over clinical assessment in many settings. ${ }^{14}$ As imaging is not always available that would limit its usefulness as a core domain. ${ }^{15}$ The ICON group formed a working group to further explore imaging and the structure domain and we plan to revisit the topic at the 2020 ISTS meeting in Valencia, Spain.

\section{Alignment with OMERACT core areas}

Eight of the nine core domains reflect the life impact core area of OMERACT. ${ }^{15}$ Apart from physical function capacity, no core domains aligned with the OMERACT core areas of (1) pathophysiological manifestations (eg, structure 69\%, palpation 13\%, range of motion 11\%), (2) death (eg, drop out 6\% agreement, adverse effects approximately $60 \%$ agreement) or (3) resource use (economic impact $40 \%$ agreement, medication use circa $60 \%$ agreement).

An interesting outcome of the ICON core domain process was the poor representation of the OMERACT core area of pathophysiological manifestations. The conventional/prevailing view of tendinopathy is that it is a local tissue pathology, which is plausibly/intuitively aligned with structure and function domains of the ICF, represented under pathophysiological manifestations concept/area in the OMERACT schema. A clear signal of the current conceptualisation of tendinopathy being more than a local tendon condition is apparent from the nine core 
tendinopathy domains not including many of the potential candidate domains that belong to the pathophysiological manifestations area in OMERACT.

There was agreement at the meeting that candidate domains such as adverse events and medication (other treatments) use would be covered generically for all trials as per reporting guidelines (eg, Consolidated Standards of Reporting Trials (CONSORT)). ${ }^{16}$ In summary, the core outcome domains for tendinopathy are predominantly of the OMERACT core area of life impact.

Candidate domains about which the group members disagreed were core domains

There was a prevailing view at the ISTS consensus meeting that candidate domains that were voted not to be core domains ( $\geq 70 \%$ disagree) may still retain use in the clinic. For example, tendon palpation and range of motion, while not core domains, will still be part of a clinical examination. Interestingly, the patient's survey had these candidate domains as core ( $\geq 70 \%$ agree).

Another example was that the measurement of sensory modality-specific pain with quantitative sensory testing was deemed to be of likely importance in stratification of groups of individuals with tendinopathy on the basis of prognosis and possibly predicting treatment outcomes, ${ }^{17}$ but not as a measure of a health-related nature and thus outcome.

\section{Strengths}

A strength of the process we undertook in deciding these core domains for tendinopathy was that it involved individuals of both sexes, experienced in either treating/researching tendinopathy from a range of professions and countries. We also surveyed patients who had been diagnosed with tendinopathy by a HCP and involved two local patients in the ISTS consensus meeting. That along with many of the HCP having also experienced tendinopathy provides a level of assurance that the core domains for tendinopathy are meaningful entities representing healthrelated domains of patients with tendinopathy. The research was conducted independent of any funding source (eg, pharma, healthcare profession associations, sponsors).

\section{Feature box}

ICON group recommends that:

- Clinical trials should include a measure for each of the nine core domains at a minimum, so that future meta-analyses will be able to better estimate treatment effects.

- These core domains should be used alongside clinical trial reporting guidelines (e.g.,) when conducting and reporting clinical trials.

- In future, core outcome sets need to be established for each of the common tendinopathies (eg, Achilles tendon, lateral elbow tendon), using these nine core domains as the guide (and an update reported at the future ISTS). Outcome measures should be valid, responsive and feasible as per the OMERACT guidelines.

- A special interest group of knowledgeable specialist radiologists and clinician scientists should discuss imaging further with a view to resolving whether tendon structure ought to be included as a core domain.

- The agreed core domains should not prevent the use of other outcomes in trials or clinical practice. The nine core domains represent the minimal reporting requirement.

\section{Limitations}

We were only able to have two local patients at the face-to-face ISTS consensus meeting and the online survey of patients was only conducted in Australia. This imposes a caveat on interpreting the patient survey responses, especially on the candidate domains of physical activity levels, medication use, clinical examination findings and range of motion (table 2). Notwithstanding this, the patient views at the consensus meeting appeared to align with the online survey.

The discussion on the structure (imaging largely) candidate domain raised the issue that we only engaged a single radiologist in the Delphi study. This was slightly offset by the three sports medicine physicians and three physiotherapists who all had published imaging studies in collaboration with radiologists. The meeting decided that further work on imaging (structure) was required and should include greater involvement of musculoskeletal radiologists who are expert in tendinopathies.

\section{Author affiliations}

${ }^{1}$ School of Health and Rehabilitation Sciences: Physiotherapy, The University of Queensland, Brisbane, Queensland, Australia

${ }^{2}$ Department of Orthopaedics and Sports Medicine, Erasmus University Medical Centre, Rotterdam, Netherlands

${ }^{3}$ Department of Community Medicine and Rehabilitation, Sports Medicine, Umeå University, Umeå, Sweden

${ }^{4}$ Oslo Sports Trauma Research Center, Department of Sports Medicine, Norwegian School of Sport Sciences, Oslo, Norway

${ }^{5}$ Aspetar Orthopaedic and Sports Medicine Hospital, Doha, Qatar

${ }^{6}$ La Trobe Sport and Exercise Medicine Research Centre, La Trobe University, Bundoora, Victoria, Australia

${ }^{7}$ Allied Health Sciences, Physiotherapy, Griffith University, Nathan, Queensland, Australia

${ }^{8}$ Department of Rehabilitation Sciences, The Hong Kong Polytechnic University, Kowloon, Hong Kong

${ }^{9}$ Department of Physical Therapy, University of Delaware, Newark, Delaware, USA ${ }^{10}$ Physiotec, Tarragindi, Queensland, Australia

${ }^{11}$ School of Health and Midwifery, University of Hertfordshire, Hertfordshire, UK

${ }^{12}$ Therapy Department, Central London Community Healthcare NHS Trust, London, UK

${ }^{13}$ Department of Physical Therapy \& Rehabilitation Science, College of Health Science, Qatar University, Doha, Qatar

${ }^{14}$ Department of Musculoskeletal Disorders, Faculty of Medicine and Surgery, University of Salerno, Salerno, Italy

${ }^{15}$ Centre for Sports and Exercise Medicine, Barts and The London School of Medicine and Dentistry, Mile End Hospitial, London, United Kingdom

${ }^{16}$ School of Pharmacy and Bioengineering, Guy Hilton Research Centre, Keele University, Stoke on Trent, England

${ }^{17}$ Department of Physical Therapy, Bispebjerg Hospital, Kobenhavn, Denmark ${ }^{18}$ Department of Sports Medicine, Bispebjerg Hospital, Kobenhavn, Denmark

${ }^{19}$ Department of Physiotherapy, Monash University, Clayton, Victoria, Australia

${ }^{20}$ Department of Radiology \& Nuclear Medicine, Erasmus MC, Rotterdam,

Netherlands

${ }^{21}$ Fortius Clinic, London, UK

${ }^{22}$ Centre for Sports \& Exercise Medicine, Queen Mary University of London, London, UK

${ }^{23}$ Department of Physical Therapy, University of British Columbia Faculty of Medicine, Vancouver, British Columbia, Canada

${ }^{24}$ Sports Medicine and Human Performance, Cardiff Metropolitan University, Cardiff, UK

${ }^{25}$ University Medical Center, Department of Orthopaedics, University of Groningen,

Groningen, Netherlands

${ }^{26}$ Aspetar Sports Groin Pain Centre, Aspetar Orthopaedic and Sports Medicine

Hospital, Doha, Qatar

${ }^{27}$ Sport Medicine and Exercise Clinic Haarlem (SBK), Haarlem, Netherlands

${ }^{28}$ Department of Orthopaedic Surgery, University of Chicago, Chicago, Illinois, USA

${ }^{29}$ Human Movement Sciences, University of Groningen, University Medical Center

Groningen, Groningen, The Netherlands

Twitter Bill Vicenzino @Bill_Vicenzino, Robert-Jan de Vos @rj_devos, Karin Gravare Silbernagel @kgSilbernagel, Alison Grimaldi @alisongrimaldi, Jeremy S Lewis @ JeremyLewisPT, Peter Malliaras @DrPeteMalliaras, Sean Mc Auliffe @Seaniemc89, Jonathan D Rees @drjrees, Ebonie Kendra Rio @tendonpain, Inge van den AkkerScheek@akkerscheeki and Johannes Zwerver @Hans Zwerver 
Contributors BV: concept, project lead, methods, data collection and analysis, writing. Other committee members R-JdV, JZ, AW, EKR, AS, SMcA: project oversight, methods, data collection, writing. Larger group: Delphi process, writing.

Funding The authors have not declared a specific grant for this research from any funding agency in the public, commercial or not-for-profit sectors.

Competing interests None declared.

Patient consent for publication Not required.

Ethics approval Ethical approval was gained for the study from the University of Queensland, Australia Ethics Committee (Approval \#2018001439).

Provenance and peer review Not commissioned; externally peer reviewed.

\section{ORCID iDs}

Bill Vicenzino http://orcid.org/0000-0003-0253-5933

Hakan Alfredson http://orcid.org/0000-0003-4109-7606

Karin Gravare Silbernagel http://orcid.org/0000-0001-7566-407X

Jeremy S Lewis http://orcid.org/0000-0001-7870-9165

Jonathan D Rees http://orcid.org/0000-0002-5477-8358

Alex Scott http://orcid.org/0000-0003-0366-8404

Johannes Zwerver http://orcid.org/0000-0002-8499-2806

\section{REFERENCES}

1 Hopkins C, Fu S-C, Chua E, et al. Critical review on the socio-economic impact of tendinopathy. Asia Pac J Sports Med Arthrosc Rehabil Technol 2016;4:9-20.

2 Gajhede-Knudsen M, Ekstrand J, Magnusson H, et al. Recurrence of Achilles tendon injuries in elite male football players is more common after early return to play: an 11-year follow-up of the UEFA champions League injury study. Br J Sports Med 2013; $47: 763-8$

3 Wilson F, Walshe M, O'Dwyer T, et al. Exercise, orthoses and splinting for treating Achilles tendinopathy: a systematic review with meta-analysis. Br J Sports Med 2018;52:1564-74

4 Everhart JS, Cole D, Sojka JH, et al. Treatment Options for Patellar Tendinopathy: A Systematic Review. Arthroscopy 2017:33:861-72.

5 Bisset L, Paungmali A, Vicenzino B. A systematic review and meta-analysis of clinica trials on physical interventions for lateral epicondylalgia * commentary. Br J Sports Med 2005;39:411-22

6 Macdermid JC, Silbernagel KG. Outcome evaluation in tendinopathy: foundations of assessment and a summary of selected measures. J Orthop Sports Phys Ther 2015;45:950-64.

7 Boers M, Kirwan JR, Wells G, et al. Developing core outcome measurement sets for clinical trials: OMERACT filter 2.0. J Clin Epidemiol 2014;67:745-53.

8 Tugwell P, Boers M, Brooks P, et al. OMERACT: an international initiative to improve outcome measurement in rheumatology. Trials 2007;8:38.

9 Boers M, Kirwan JR, Tugwell P, et al. The OMERACT Handbook [Internet]. OMERACT. Available: http://www. omeract. org/pdf

10 Scott A, Squier K, Alfredson H, et al. Icon 2019: international scientific tendinopathy symposium consensus: clinical terminology. Br J Sports Med 2020;54:260-2

11 Rio EK, Mc Auliffe S, Kuipers I, et al. Icon PART-T 2019-International scientific tendinopathy symposium consensus: recommended standards for reporting participant characteristics in tendinopathy research (PART-T). Br J Sports Med 2019:doi: 10.1136/bjsports-2019-100957. [Epub ahead of print 13 Sep 2019].

12 de Villiers MR, de Villiers PJT, Kent AP. The Delphi technique in health sciences education research. Med Teach 2005:27:639-43.

13 Fink A, Kosecoff J, Chassin M, et al. Consensus methods: characteristics and guidelines for use. Am J Public Health 1984:74:979-83.

14 Docking SI, Ooi CC, Connell D. Tendinopathy: is imaging telling us the entire story? J Orthop Sports Phys Ther 2015:45:842-52.

15 Parker L, Nazarian LN, Carrino JA, et al. Musculoskeletal imaging: Medicare use, costs, and potential for cost substitution. J Am Coll Radio/ 2008;5:182-8.

16 Moher D, Hopewell S, Schulz KF, et al. Consort 2010 explanation and elaboration: updated guidelines for reporting parallel group randomised trials. BMJ 2010;340:c869.

17 Coombes BK, Bisset L, Vicenzino B. Cold hyperalgesia associated with poorer prognosis in lateral epicondylalgia: a 1-year prognostic study of physical and psychological factors. Clin J Pain 2015;31:30-5.

18 Brinks A, van Rijn RM, Willemsen SP, et al. Corticosteroid injections for greater trochanteric pain syndrome: a randomized controlled trial in primary care. Ann Fam Med 2011;9:226-34.

19 Mellor R, Bennell K, Grimaldi A, et al. Education plus exercise versus corticosteroid injection use versus a wait and see approach on global outcome and pain from gluteal tendinopathy: prospective, single blinded, randomised clinical trial. BMJ 2018;361.

20 Munteanu SE, Scott LA, Bonanno DR, et al. Effectiveness of customised foot orthoses for Achilles tendinopathy: a randomised controlled trial. Br J Sports Med 2015;49:989-94

21 Horstmann T, Jud HM, Fröhlich V, et al. Whole-Body vibration versus eccentric training or a Wait-and-See approach for chronic Achilles tendinopathy: a randomized clinical trial. J Orthop Sports Phys Ther 2013;43:794-803.

22 Rio E, van Ark M, Docking S, et al. Isometric contractions are more analgesic than isotonic contractions for Patellar tendon pain: an In-Season randomized clinical trial. Clin J Sport Med 2017;27:253-9.

23 Thijs KM, Zwerver J, Backx FJG, et al. Effectiveness of shockwave treatment combined with eccentric training for Patellar tendinopathy: a double-blinded randomized study. Clin J Sport Med 2017:27:89-96.

24 Beyer R, Kongsgaard M, Hougs Kjær B, et al. Heavy slow resistance versus eccentric training as treatment for Achilles tendinopathy. Am J Sports Med 2015:43:1704-11.

25 Silbernagel K, Thomeé R, Eriksson B, et al. Using a Pain-Monitoring model, during rehabilitation in patients with. Am J Sport Med 2007:35:897-906.

26 Zwerver J, Hartgens F, Verhagen E, et al. No effect of extracorporeal shockwave therapy on Patellar tendinopathy in jumping athletes during the competitive season. Am J Sports Med 2011;39:1191-9.

27 Coombes BK, Bisset L, Brooks P, et al. Effect of corticosteroid injection, physiotherapy, or both on clinical outcomes in patients with unilateral lateral Epicondylalgia. JAMA 2013;309:461-9.

28 Stasinopoulos D, Stasinopoulos I. Comparison of effects of eccentric training, eccentric-concentric training, and eccentric-concentric training combined with isometric contraction in the treatment of lateral elbow tendinopathy. J Hand Ther 2017;30:13-19.

29 Yelland MJ, Sweeting KR, Lyftogt JA, et al. Prolotherapy injections and eccentric loading exercises for painful Achilles tendinosis: a randomised trial. Br J Sports Med 2011:45:421-8. 